
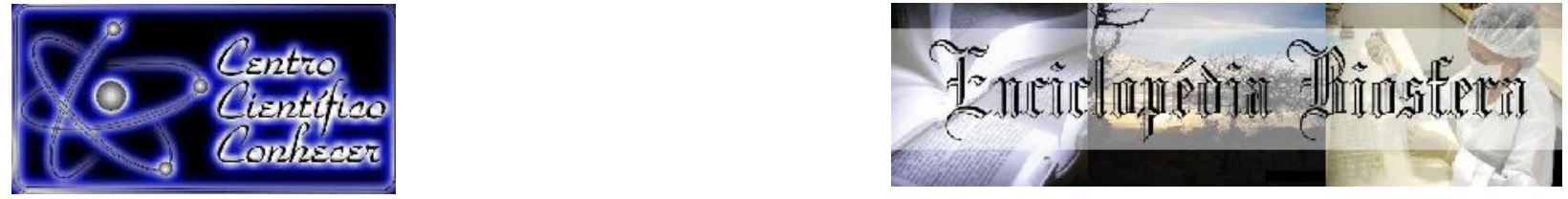

\title{
ALTERAÇÕES NOS ATRIBUTOS QUÍMICOS DE UM ARGISSOLO AMARELO, SUBMETIDO A TRÊS DIFERENTES AGROECOSSISTEMAS
}

\author{
Lisandra Cristine Monteiro Blanco ${ }^{1}$; Marcus Victor Almeida Campos ${ }^{2}$; Seidel \\ Ferreira dos Santos ${ }^{3}$; Gleidson Marques Pereira ${ }^{4}$ \\ ${ }^{1}$ Graduada em Engenharia Ambiental, Universidade do Estado do Pará, Belém, \\ Pará, Brasil. lisandrac.blanco@gmail.com \\ ${ }^{2}$ Graduado em Engenharia Ambiental, Universidade do Estado do Pará, Belém, \\ Pará, Brasil. marcusvictor.campos@gmail.com. \\ ${ }^{3}$ Doutor em Biodiversidade e Biotecnologia da Rede Bionorte, Universidade Federal \\ do Amazonas, Manaus, Amazonas, Brasil. botanish@yahoo.com.br \\ ${ }^{4}$ Mestre em Solos e Nutrição de Plantas, Universidade Federal do Ceará, \\ Fortaleza, Ceará, Brasil. agro_gleidson@yahoo.com.br
}

Recebido em: 22/09/2018 - Aprovado em: 23/11/2018 - Publicado em: 03/12/2018 DOI: 10.18677/EnciBio 2018B54

RESUMO
Historicamente, o Brasil é um país em que a produção agrícola apresenta uma de suas maiores características econômicas, entretanto, nas últimas décadas foram construídas políticas públicas que visassem uma maior inserção da agricultura familiar. Esta prática se não feita com um bom manejo, pode se tornar extremamente prejudicial às propriedades físicas, biológicas e químicas do solo. Desse modo, o uso de parâmetros ambientais para solo, estabelecem o nível de degradação ambiental em que se encontram, direcionando ações preventivas, de correção e controle. Objetivou-se analisar as alterações nos atributos químicos de um argissolo amarelo, localizado nas proximidades do município de Eldorado dos Carajás - Pará, submetido a diferentes agroecossistemas: pastagens com 1 e 2 anos de reforma e Mata Nativa. A coleta de dados foi realizada a partir do segundo semestre de 2017, durante os meses de novembro e dezembro. Diante do resultado encontrado, de acordo com a metodologia utilizada, em muitos momentos os atributos químicos avaliados se demonstraram satisfatórios no decorrer do tempo quando comparados à Mata nativa, a exemplo da salinização e acidez potencial (prejudiciais ao solo) em que o menor valor obtido foi para a pastagem com 2 anos de reforma. Além disso, o valor encontrado individualmente em cada um dos parâmetros permitiu avaliar a propriedade química para qual deve-se direcionar maior atenção, funcionando como instrumento de avaliação e controle da degradação ambiental em que os solos se encontram.

PALAVRAS-CHAVE: desempenho, parâmetros, população. 


\title{
CHANGES IN THE CHEMICAL ATTRIBUTES OF A YELLOW ARGISSOL, SUBMITTED TO THREE DIFFERENT AGROECOSYSTEMS
}

\begin{abstract}
Historically, Brazil is a country in which agricultural production presents one of its greatest economic characteristics, however, in the last decades, public policies have been constructed that aim at a greater insertion of family agriculture. This practice, if not done with good management, can become extremely harmful to the physical, biological and chemical properties of the soil. Thus, the use of environmental parameters for soil establishes the level of environmental degradation in which they are, directing preventive, corrective and control actions. The objective of this study was to analyze the changes in the chemical attributes of a yellow argisol, located in the vicinity of Eldorado dos Carajás - Pará, under different agroecosystems: pastures with 1 and 2 years of reforestation and primary forest. Data collection was performed from the second half of 2017, during the months of November and December. In view of the result found, according to the methodology used, in many cases the chemical attributes evaluated were satisfactory over time when compared to the native forest, such as salinization and potential acidity (harmful to the soil), where the lowest value obtained went to the pasture with 2 years of reform. In addition, the value found individually in each of the parameters allowed to evaluate the chemical property to which more attention should be directed, functioning as an instrument of evaluation and control of the environmental degradation in which the soils are found.
\end{abstract}

KEYWORDS: parameters, performance, population.

\section{INTRODUÇÃO}

Historicamente, o Brasil é um país em que o fator de produção 'terra' apresenta uma de suas maiores características, o desenvolvimento agrícola como um dos principais gêneros de sua economia. Nesse sentido, tal perfil passou a receber grandes incentivos principalmente por ações governamentais, gerando modernização por meio da incorporação e consequente aumentos na produtividade das culturas (MOREIRA;TEXEIRA, 2014).

O setor agrícola brasileiro durante muito tempo esteve extremamente atrelado ao grande produtor com uma produção latifundiária, de monocultura e voltada ao mercado externo, entretanto, nas últimas décadas foram construídas políticas públicas que visassem uma maior inserção da agricultura familiar e, dessa maneira, diversificasse a produção e o uso do solo, fortalecendo não apenas o setor econômico, mas social (PEREIRA; NASCIMENTO, 2014).

Nesse sentido, em relação ao uso do solo para produção agrícola na Amazônia brasileira, há grande diversificação e destaques para determinados sistemas de produção: Sistema de Plantio Direto (SPD), Sistema Convencional de Cultivo (SCC), Rotação de Culturas e Agricultura Familiar, sendo este último estruturalmente diversificado (produção de alimentos para subsistência, pastagem. Esta forma de produção geralmente é determinada de acordo com as demandas do mercado (BONINI et al., 2013).

Desse modo, tal modelo de agricultura representa uma das formas de ocupação da Amazônia, o que significa a alteração do ambiente natural para o desenvolvimento de áreas agrícolas a exemplo da formação de pastagem por meio da derrubada e queima da flora (LISBOA; MIRANDA, 2014). 
De maneira geral, a agricultura familiar representa uma alternativa para uma produção agrícola menos excludente e mais sustentável, entretanto, quando não é executada sem o manejo adequado, leva a diminuição da qualidade produtiva do solo (SANTOS; CÂNDIDO, 2013). Algumas dessas práticas relacionadas a agricultura convencional são degenerativas ao solo, ocasionando perda em sua sustentabilidade, propriedades físicas, químicas e biológicas, de fertilidade fixação da vegetação (BRANDÃO, 2013).

A pastagem pode se tornar um dos sistemas mais degradantes ao solo, principalmente quando usa práticas como a queima, gerando erosão, redução do teor de matéria orgânica e nutrientes do solo e alteração do $\mathrm{pH}$, ou seja, geram severas alterações nos atributos físicos e químicos do solo (GUIMARÃES et al., 2014).

Novas práticas de plantio começaram a ser desenvolvidas e uma forma de mensurar seu grau de sustentabilidade é por meio de indicadores. De acordo com a EMBRAPA (2003), os indicadores de sustentabilidade em agroecossistemas são definidos por meio de 'descritores' que são características relevantes de um dado sistema. Desse modo, para cada descritor são definidos um ou mais indicadores para avaliar a forma que esses sistemas se comportam.

Dessa maneira, a Qualidade Ambiental avalia os atributos e características do ambiente que afetam tanto o homem como outros organismos (VAZ; SILVEIRA, 2014), estando o ambiente atrelado a toda parcela da biosfera resultante de interações físicas, químicas, biológicas, sociais, econômicas e culturais, as quais sofrem influência de fatores físicos, bióticos e antropogênicos (MACEDO, 2015).

A forma de avaliar a qualidade do ambiente e se as interações estão sofrendo algum tipo de modificação, alteração ou impacto, é por meio de ferramentas como os indicadores. Nesse sentido, a utilização de indicadores são de suma importância para a avaliação do solo, de modo que possibilitam a adoção antecipada de ações de controle ou correção do mesmo, contribuindo na identificação do aumento ou diminuição da sustentabilidade de determinado sistema de produção (VICENTE; ARAUJO, 2013).

Dessa forma, a avaliação da sustentabilidade de agroecossistemas não apenas se fez necessária para avaliar o grau de degradação ambiental que determinado sistema de plantio poderia estar ocasionando, mas como maneira de amenizar tais impactos por meio de tecnologias que desenvolvessem sistemas produtivos menos degradantes, ou seja, uma agricultura sustentável com bases ecológicas de maneira a atender demandas sociais e questões de saúde, ambiente e economia (CAPELLESSO; CAZELLA, 2013).

Diante disso, objetivou-se analisar as alterações nos atributos químicos de um argissolo amarelo, submetido a três diferentes agroecossistemas: sistemas de pastagem com 1 e 2 anos de reforma, e floresta primária.

\section{Área de Estudo}

\section{MATERIAL E METODOS}

O estudo foi conduzido na propriedade rural (Santa Lúcia), pertencente ao projeto de Assentamento São Francisco, identificado no sentindo do município de Eldorado dos Carajás, sudeste do Estado do Pará. Sua localização está entre as

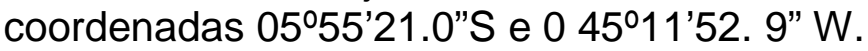




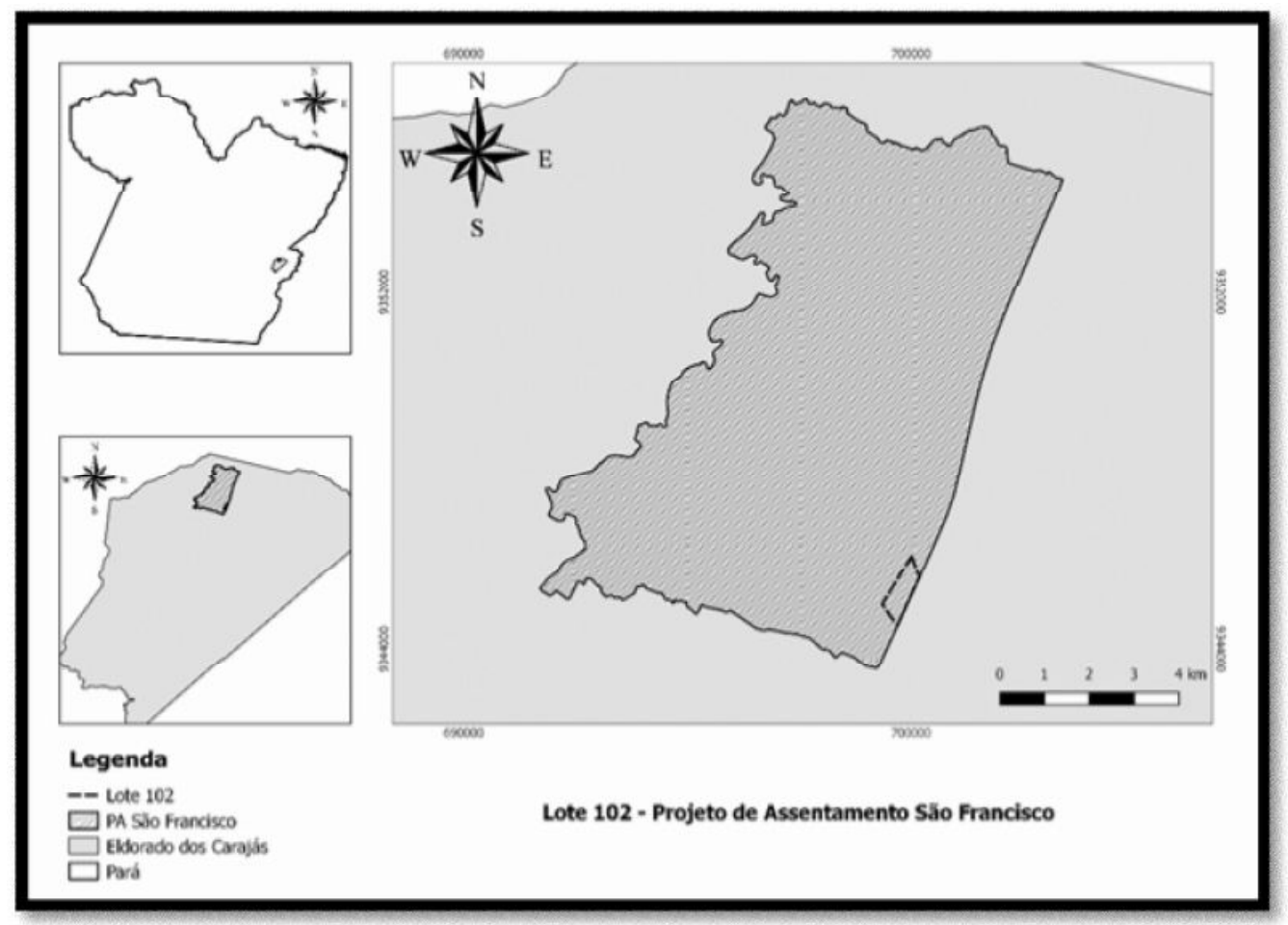

FIGURA 1. Mapa de localização da Área de Estudo. Fonte: Autores, 2018.

A título comparativo dos indicadores avaliados, a área de estudo foi dividida em três: pasto com 1 ano de reforma do solo (PR1), pasto com 2 anos de reforma (PR2) e mata nativa (MN).

\section{Delineamento Experimental e Coleta das Amostras de Solo}

$O$ delineamento utilizado no presente estudo foi inteiramente casualizado sendo 3 os tratamentos comparados através da análise química do solo: pasto com 1 ano de reforma do solo (PR1), pasto com 2 anos de reforma (PR2) e mata nativa $(\mathrm{MN})$, sendo cada tratamento apresentando 4 repetições.

As amostras de solo do sítio Santa Lúcia foram coletadas no segundo semestre de 2017, por ser o período mais seco da região, durante os meses de novembro e dezembro. As amostras foram coletadas a $5 \mathrm{~cm}$ de profundidade com auxílio de um trado calador e uma marreta.

Após a coleta de amostras e retirada de ponto no GPS foi feito a mistura dentro dos baldes e passados para 3 sacos de coleta os quais foram identificados e guardados em uma caixa térmica para não perder as propriedades da amostra para fins de análise laboratorial e manter a temperatura estável do momento de retirada do ambiente de origem.

Foi realizada a mensuração de cada recipiente utilizado na coleta 24 horas antes da visita. No Laboratório, as amostras foram levadas a uma balança para que se pudesse obter seus pesos úmidos. Após o processo de pesagem de todos os recipientes ter sido concluído, as amostras foram levadas para a estufa a $105^{\circ} \mathrm{C}$ por 24 horas. Com o passar das 24 horas, as amostras foram retiradas e levadas novamente para a balança para que assim fosse obtido o peso seco das amostras.

Posteriormente, as amostras foram levadas para análise química de solos e consequente obtenção dos resultados. 


\section{Análise Química do solo}

Foram determinados os atributos químicos para análise da fertilidade do solo (QUADRO 1), conforme metodologia empregada pela Embrapa (2009).

QUADRO 1 - Atributos Químicos e métodos de análise para cada amostra. Fonte: Autores, 2018.

\begin{tabular}{|c|c|}
\hline Atributo & Método \\
\hline Teor de matéria orgânica & Determinado pelo método de Walkley e Black (1934) \\
\hline Nitrogênio total (N) & Método de Kjeldahl por destilação a vapor \\
\hline Determinação do pH & $\begin{array}{l}\mathrm{O} \mathrm{pH} \text { do solo foi medido por meio de eletrodo } \\
\text { combinado (potenciômetro) imerso em suspensão } \\
\text { solo: líquido (água, } \mathrm{KCl} \text { ou } \mathrm{CaCl}_{2} \text { ) }\end{array}$ \\
\hline $\begin{array}{l}\text { Determinação de Sódio }\left(\mathrm{Na}^{+}\right) \\
\text {e Potássio }\left(\mathrm{K}^{+}\right)\end{array}$ & $\begin{array}{l}\text { O sódio e o potássio foram extraídos com a solução de } \\
\text { Mehlich } 1\left(\mathrm{HCl} \text { a } 0,5 \mathrm{~N}+\mathrm{H}_{2} \mathrm{SO}_{4} \text { a } 0,025 \mathrm{~N}\right) \text {. O primeiro } \\
\text { determinado em colorímetro e o segundo fotômetro } \\
\text { de chama. }\end{array}$ \\
\hline Determinação de Fósforo (P) & $\begin{array}{l}\text { O fósforo foi retirado com a solução de Mehlich e } \\
\text { determinado por espectrofotometria (Biospectro - } \\
\text { SP- 220) }\end{array}$ \\
\hline $\begin{array}{l}\text { Cálcio e Magnésio trocáveis } \\
\left(\mathrm{Ca}^{2+} \text { e } \mathrm{Mg}^{2+}\right)\end{array}$ & $\begin{array}{l}\mathrm{O} \mathrm{Ca}^{2+} \text { e } \mathrm{Mg}^{2+} \text { foram extraídos em } \mathrm{KCl} \text { a } 1 \mathrm{~N} \mathrm{e} \\
\text { determinados por titulação de EDTA } 0,025 \mathrm{~N}\end{array}$ \\
\hline $\begin{array}{l}\text { Acidez potencial: Hidrogênio } \\
\left(\mathrm{H}^{+}\right)+\text {Alumínio }\left(\mathrm{Al}^{3+}\right)\end{array}$ & $\begin{array}{l}\text { Foram determinados por titulometria, usando-se } \\
\text { solução de acetato de cálcio } 1 \mathrm{~N} \text { a pH } 7 \text { para sua saída } \\
\text { com EDTA - } \mathrm{Na} \text { (acidez potencial) }\end{array}$ \\
\hline $\begin{array}{l}\text { Capacidade de Troca de } \\
\text { Cátions ou CTC (T) em pH } 7 \text { e } \\
\text { a Saturação por Bases (V) }\end{array}$ & $\begin{array}{l}\mathrm{T}=\left(\mathrm{Ca}^{2+}+\mathrm{Mg}^{2+}+\mathrm{Na}^{+}+\mathrm{K}^{+}\right)+\left(\mathrm{H}^{+}+\mathrm{Al}^{3+}\right) \\
\mathrm{V}=100\left(\mathrm{Ca}^{2+}+\mathrm{Mg}^{2+}+\mathrm{Na}^{+}+\mathrm{K}^{+}\right) / \mathrm{T}\end{array}$ \\
\hline
\end{tabular}

\section{Análise de Dados}

Os dados foram tabelados e a análise de dados foi realizada por meio de estatística descritiva, submetidos a análises de variância (ANOVA). O tratamento e comparação das médias foi realizada por meio do teste de Tukey a $5 \%$ de probabilidade realizada no software estatístico SISVARß) (FERREIRA, 2014) para verificar a diferença dos teores e taxas dos atributos estudados entre áreas escolhidas.

\section{RESULTADOS E DISCUSSÃO}

A Tabela 1 apresenta todos as médias dos atributos químicos em suas respectivas unidades de medida analisados de acordo com o tempo de adoção de manejo em comparativo à mata nativa $(\mathrm{MN})$, servindo como referência para relacionar as demais áreas do estudo. Vale ressaltar que o que está sendo avaliado é o desvio das características em relação ao solo em suas condições naturais, não significando que a MN esteja em condições ideais para o cultivo agrícola. Pelo fato de todas as amostras terem sido retiradas a uma profundidade de $5 \mathrm{~cm}$, não foi necessário adotar esta variável. 
TABELA 1- Médias dos atributos (MO, N, K, Na, Al) analisados de acordo com a Mata Nativa e os agroecossistemas de pastagem em diferentes tempos de reforma

\begin{tabular}{lcccccc}
\hline $\begin{array}{l}\text { Tempo de } \\
\text { Adoção }\end{array}$ & $\begin{array}{c}\mathrm{MO} \\
\left(\mathrm{g} \mathrm{kg}^{-1}\right)\end{array}$ & $\begin{array}{c}\mathrm{N} \\
(\%)\end{array}$ & $\begin{array}{c}\mathrm{P} \\
\left(\mathrm{mg} \mathrm{dm}^{-3}\right)\end{array}$ & $\begin{array}{c}\mathrm{K} \\
\left(\mathrm{mg} \mathrm{dm}^{-3}\right)\end{array}$ & $\begin{array}{c}\mathrm{Na} \\
\left(\mathrm{mg} \mathrm{dm}^{-3}\right)\end{array}$ & $\begin{array}{c}\mathrm{Al} \\
\left(\mathrm{cmolc} \mathrm{dm}^{-3}\right)\end{array}$ \\
\hline Mata Nativa & $57,03 \mathrm{a} 2$ & $0,26 \mathrm{a} 2$ & $2,06 \mathrm{a} 1$ & $76,58 \mathrm{a} 1$ & $11,63 \mathrm{a} 2$ & $0,1 \mathrm{a} 1$ \\
PR1 & $42,42 \mathrm{a} 1$ & $0,18 \mathrm{a} 1$ & $22,55 \mathrm{a} 3$ & $106,12 \mathrm{a} 2$ & $6,58 \mathrm{a} 1$ & $0,14 \mathrm{a} 1$ \\
PR2 & $40,70 \mathrm{a} 1$ & $0,16 \mathrm{a} 1$ & $13,48 \mathrm{a} 2$ & $86,39 \mathrm{a} 1$ & $6,4 \mathrm{a} 1$ & $0,1 \mathrm{a} 1$ \\
\hline DMS $^{*}$ & 7,01 & 0,04 & 4,48 & 12,36 & 2,08 & 0,05 \\
\hline${\text { CV}(\%)^{* *}}^{*}$ & 7,59 & 9,72 & 17,85 & 6,98 & 12,83 & 24,57 \\
\hline
\end{tabular}

${ }^{*}$ DMS - diferença mínima significante: médias de mesmas letras e números não diferem entre si pelo Teste Tukey a 5\% de probabilidade. ${ }^{* *} \mathrm{CV}(\%)$ - coeficiente de variação. Fonte: Autores, 2018.

De acordo com a análise do atributo químico matéria orgânica (MO), tem-se o valor de 42,42 para o pasto com 1 ano de reforma (PR1); 40,70 para o pasto com 2 anos de reforma (PR2) e 57,03 para a Mata Nativa (MN), ressaltando-se que o pasto com 1 ano de reforma significa o crescimento da biomassa, maior ciclagem dos nutrientes, e consequentemente, aumento na quantidade de M.O. Enquanto que o pasto com 2 anos de reforma já começou a haver consumo da biomassa, logo há diminuição no teor de MO.

Diante disso, se assemelha aos resultados obtidos por Marchini et al. (2015), em que determinado solo sob diferentes tipos de manejo foi avaliado e constatou-se que a vegetação natural (cerrado na pesquisa em questão) apresentava o maior teor de MO em comparação com o solo exposto e diferentes tipos de tratamento para a recuperação. Todos os tratamentos eram compostos pela árvore da espécie Astronium fraxinifolium (Benth.), e a segunda maior quantidade de MO foi encontrada no tratamento que além dessa espécie arbórea ainda levava outra espécie gramínea Brachiaria decumbens (Rendel),ou seja, quanto maior a inserção e renovação de biomassa em determinado sistema, maior é a quantidade de $\mathrm{MO}$ gerada.

Segundo Costa et al., (2013), a quantidade de MO influencia nas propriedades físicas, químicas e biológicas do solo, refletindo na estabilidade e produtividade dos agroecossistemas. Sua ciclagem é definida por meio das taxas de deposição, decomposição e renovação dos resíduos (vegetais e animais). Dependendo do sistema de manejo adotado, seu teor pode aumentar, diminuir ou manter em relação a vegetação nativa.

Muitos indicadores da qualidade do solo estão extremamente vinculados a exemplo da capacidade de troca de cátions (CTC), disponibilidade nutricional às plantas e sua perda pode levar a infertilidade e redução da capacidade produtiva da terra (DECHEN et al., 2015).

Em relação a taxa de Nitrogênio $(\mathrm{N})$ presente no solo a quantidade de acordo com a Mata Nativa foi de 0,26 . De acordo com Meneghin et al. (2008), o nitrogênio é um importante elemento pois é um dos principais fatores limitantes para o desenvolvimento da vegetação já que tem relação direta com a fotossíntese, sendo constituinte da clorofila, vitaminas, carboidratos e proteínas, além de sua atuação no sistema radicular. Mais uma vez um valor mais alto entre os pastos foi para o PR1 $(0,18)$ e um decréscimo no PR2 $(0,16)$.

Para a transformação do Nitrogênio orgânico na sua forma inorgânica (mineralização ou imobilização) deve-se levar em consideração as características 
físico-químicas do solo: fertilidade do solo, textura, acidez, entre outros fatores que afetam diretamente a quantidade e taxas de $\mathrm{N}$ mineralizada (CARNEIRO et al., 2013)

Os resultados obtidos para o Fósforo $(\mathrm{P})$, mostram que o menor valor (e mais destoante) foi o da MN com 2,06; o maior de 22,55 para o PR1 e um intermediário 13,48 para o PR2. Isso deve-se ao fato que sob a perspectiva de fertilidade do solo, independentemente de suas características químicas, a disponibilidade do fósforo está vinculada a facilidade com que repõe a solução do solo. Dessa forma, em solos naturais, a disponibilidade e absorção de $\mathrm{P}$ pelas plantas depende de suas formas inorgânicas e orgânicas de labilidade intermediária, enquanto que em solos com alguma adição de fertilizantes forma-se uma camada superficial com alta disponibilidade de nutrientes, ocasionando o acúmulo de P (SANTOS et al., 2008).

Os teores para potássio $(\mathrm{K})$ de acordo com as variáveis analisadas e seus respectivos valores médios foram 76,58 para $M N$; 106,12 para PR1 e 86,39 para PR2. Sendo assim, foi constatado um aumento no teor deste atributo nos sistemas de pastagem e o maior valor no primeiro ano, mais uma vez seguindo a ideia que logo no primeiro ano há menor consumo de nutrientes em relação a uma vegetação com 2 anos de reforma, aliado ao fato que com a inserção de adubos para a recuperação dos solos, cria-se uma maior disponibilidade de atributos em relação a $\mathrm{MN}$.

De acordo ainda com a tabela 2, os teores de sódio presentes no solo sob os sistemas de pastagem não variaram significativamente entre si, sendo 6,58 para PR1 e 6,40 para PR2, entretanto, foram bem menores em relação ao valor da MN de 11,55 ; o que indicou uma significativa redução da salinização do solo nos agroecossistemas de pastagem.

Fazer um bom manejo requer levar em consideração a fertilidade real do solo, o estado e necessidade nutricional da planta, e taxa de absorção da cultura; evitando-se além do desperdício de fertilizantes, a salinização do solo (acúmulo de íons como $\mathrm{Na}^{+}, \mathrm{Ca}^{2+}, \mathrm{Mg}^{2+}, \mathrm{Cl}^{-}$e $\mathrm{SO}_{4}^{-2}$ ), pois a excessiva aplicação de fertilizantes pode ocasionar a salinização do solo, a qual é extremamente prejudicial por acarretar severos danos ao desenvolvimento vegetal, afetando seu consumo hídrico, diminuição do teor de água no solo, degradação e possível desertificação de áreas antes agricultáveis (SILVA, 2014; SILVA, 2015).

Em relação a quantidade de alumínio $\left(\mathrm{Al}^{3+}\right)$, os valores demonstraram-se relativamente constantes de acordo com a profundidade estudada, o que é visto de maneira positiva, pois quanto maior a quantidade de alumínio presente no solo, maior é a sua toxicidade.

De acordo com os atributos abordados no presente trabalho, em um estudo realizado por Maia (2013), este grupo de atributos foi considerado como parte de indicadores que apresentam efeito negativo ao solo, ou seja, "quanto menor sua quantidade melhor", o $\mathrm{Al}, \mathrm{Na}$ e saturação de alumínio $(\mathrm{m} \%)$. Dentre os atributos que contribuem de maneira positiva para a qualidade do solo até determinado valor, o $\mathrm{pH}, \mathrm{P}, \mathrm{K}, \mathrm{H}+\mathrm{Al}, \mathrm{Ca}+\mathrm{Mg}, \mathrm{CTC}$ e V\%.

Os valores de cálcio e magnésio também apresentaram significância em seus resultados em que o menor valor foi o de PR1 $(3,6)$, aumentando para PR2 $(5,45)$ e 7,03 para a mata nativa. Conforme verificado na Tabela 2. 
TABELA 2 - Médias dos atributos ( $\mathrm{Ca}+\mathrm{Mg}, \mathrm{pH}, \mathrm{H}+\mathrm{Al}, \mathrm{CTC}$ total, CTC efetiva, $\mathrm{V} \%$ e m\%) analisados de acordo com a Mata Nativa e os agroecossistemas de pastagem em diferentes tempos de reforma

\begin{tabular}{cccccccc}
\hline $\begin{array}{c}\text { Tempo de } \\
\text { Adoção }\end{array}$ & $\begin{array}{c}\mathrm{Ca}+\mathrm{Mg} \\
\left(\mathrm{cmolc} \mathrm{dm}^{-3}\right)\end{array}$ & $\begin{array}{c}\mathrm{pH} \\
\left(\mathrm{H}_{2} \mathrm{O}\right)\end{array}$ & $\begin{array}{c}\mathrm{H}+\mathrm{Al} \\
\left(\mathrm{cmolc} \mathrm{dm}^{-3}\right)\end{array}$ & $\begin{array}{c}\mathrm{CTC} \text { Total } \\
\left(\mathrm{cmolc} \mathrm{dm}^{-3}\right)\end{array}$ & $\begin{array}{c}\text { CTC Efetiva } \\
\left(\mathrm{cmolc} \mathrm{dm}^{-3}\right)\end{array}$ & V\% & $\mathrm{m} \%$ \\
\hline Mata Nativa & $7,03 \mathrm{a} 3$ & $5,18 \mathrm{a} 1$ & $6,6 \mathrm{a} 2$ & $14,76 \mathrm{a} 2$ & $7,38 \mathrm{a} 3$ & $50,52 \mathrm{a} 2$ & $1,37 \mathrm{a} 1$ \\
PR1 & $3,60 \mathrm{a} 1$ & $5,05 \mathrm{a} 1$ & $6,06 \mathrm{a} 2$ & $10,58 \mathrm{a} 1$ & $4,23 \mathrm{a} 1$ & $38,58 \mathrm{a} 1$ & $2,99 \mathrm{a} 1$ \\
PR2 & $5,45 \mathrm{a} 2$ & $5,88 \mathrm{a} 2$ & $3,88 \mathrm{a} 1$ & $9,59 \mathrm{a} 1$ & $5,82 \mathrm{a} 2$ & $59,62 \mathrm{a} 3$ & $1,73 \mathrm{a} 1$ \\
\hline DMS $^{*}$ & 0,70 & 0,35 & 0,96 & 1,74 & 0,73 & 4,89 & 1,78 \\
\hline${\text { CV }(\%)^{* *}}^{* *}$ & 6,57 & 3,32 & 8,78 & 7,57 & 6,40 & 5,00 & 44,07 \\
\hline
\end{tabular}

*DMS - diferença mínima significante: médias de mesmas letras e números não diferem entre si pelo Teste Tukey a 5\% de probabilidade. ${ }^{* *} \mathrm{CV}(\%)$ - coeficiente de variação. Fonte: Autores, 2018.

$\mathrm{O} \mathrm{pH}$ em água é um atributo, o qual mais interfere na disponibilidade de nutrientes às plantas. A faixa considerada ótima para que ocorra a disponibilidade máxima de macronutrientes e MO é o pH entre 6,0 e 6,5; pois afasta do mínimo a disponibilização dos micronutrientes, reduzindo a acidez do solo que é um fator limitante da produção agrícola (DUARTE et al., 2013). Desse modo, os resultados dos valores médios deste parâmetro foram de 5,05 para PR1; 5,18 para a mata nativa e o maior, o qual mais se aproximou de um pH considerado 'ótimo' foi PR2 $(5,88)$.

O parâmetro $\mathrm{H}+\mathrm{Al}$ (acidez potencial) sofreu variações, demonstrando significância para as variáveis analisadas: o maior valor foi o da Mata Nativa $(6,6)$; decrescendo para 6,07 no PR1 e o menor valor foi do PR2 com 3,88.

O processo de acidificação acentua-se com a remoção de cátions trocáveis da superfície dos colóides, excesso de alumínio e manganês por exemplo, por meio da água da chuva (solo muito exposto - lixiviação), decomposição de minerais argilosos e MO, troca iônica das raízes e uso de fertilizantes nitrogenados acidificam o solo (NATALE et al., 2012).

Nesse sentido, na camada superficial do solo usualmente nota-se uma maior acidez, pelo fato de apresentar grande quantidade de $\mathrm{MO}$, nutrientes, podendo contribuir para as reações de complexação de $\mathrm{H}^{+}$e $\mathrm{Al}^{+3}$, visto que o $\mathrm{He}$ el trocáveis tem forte relação com o pH, influenciando na acidificação do solo e rendimento das culturas. Desse modo, a quantidade de $\mathrm{H} \mathrm{e} \mathrm{Al} \mathrm{tendeu} \mathrm{a} \mathrm{diminuir} \mathrm{nas} \mathrm{pastagens} \mathrm{de}$ reforma pelo fato da aplicação de correções (via calagem) da acidez de seus solos, e se feitas de forma eficiente e correta, com o passar do tempo, conseguem diminuir ainda mais a acidez como foi o caso do PR2.

Em relação a CTC total, este atributo está relacionado a capacidade de troca de cátions que o solo possui. Tais cátions estão retidos nos colóides que são as partículas de argila e MO formadoras do solo. Geralmente, quanto maior a CTC do solo, maior será sua fertilidade, pois adsorve nutrientes essenciais a vegetação (ANDREOTTI et al., 2015).

De acordo com as análises realizadas, o maior teor foi para a Mata Nativa $(14,76)$; seguido do PR1 $(10,58)$ e o menor valor foi do PR2 $(9,59)$. Nos resultados de CTC efetiva, o maior valor continuou sendo para a Mata Nativa $(7,38)$, entretanto, o maior valor entre as pastagens foi de PR2 $(5,82)$ e o menor ficou com PR1 $(4,23)$; podendo ser uma consequência da acidez do solo $(\mathrm{H}+\mathrm{Al})$, uma vez que PR2 apresenta menor acidez potencial em relação a PR1, pois segundo Sarto et al. (2014), com a acidificação sucede a liberação de íons $H+$ para a solução do solo, e por meio do mecanismo antiporte, ocorre a manutenção do equilíbrio iônico no 
interior das células das raízes das plantas, absorvendo e reduzindo cátions como $\mathrm{Ca}^{2+}, \mathrm{Mg}^{2+}$ e $\mathrm{K}^{+}$(essenciais as plantas).

Nesse contexto, é de suma a importância a contribuição da matéria orgânica para a CTC dos solos sob condições tropicais, pois favorece a retenção de cátions e diminui as perdas por lixiviação (FREITAS et al., 2013), o que pode também ter influenciado na CTC do PR2 já que apresenta o menor teor de MO.

A respeito do parâmetro saturação de bases (V\%), Silva et al. (2017) afirma que é um importante indicador do estado geral de fertilidade do solo, visto que por meio de seus percentuais define-se o caráter eutrófico e distrófico do solo. A partir das análises realizadas, os resultados foram: $50,52 \%$ para a Mata Nativa; $38,58 \%$ para PR1 e o maior para PR2 (59, 62\%), considerado bom.

Para o atributo saturação de Alumínio $(\mathrm{m} \%)$, os percentuais encontrados foram considerados baixos nos três casos, sendo 1,37\%; $2,99 \%$ e $1,73 \%$ para Mata Nativa, PR1 e PR2 respectivamente. A média do teor que apresentou um leve aumento foi PR1, mas ainda assim considerado baixo, lembrando que no caso dos sistemas de pastagem, os valores são pequenos por conta das práticas de correção da acidez do solo.

\section{CONCLUSÃO}

O teste Tukey a nível de $5 \%$ de significância, evidenciou diferença significativa entre a maiorias dos tratamentos exceto para concentração (Al) e saturação de alumínio (m\%).

A área de mata nativa apresentou maiores valores para os parâmetros de $\mathrm{MO}, \mathrm{N}, \mathrm{Na}, \mathrm{Ca}+\mathrm{Mg}, \mathrm{H}+\mathrm{Al}, \mathrm{CTC}$ total e Efetiva, em comparação as áreas de pasto com 1 e 2 anos de reforma. As áreas de pastagem apresentaram maior Saturação de alumínio (m\%) e base ( $\mathrm{v} \%$ ), $\mathrm{PH}$ e concentrações de Alumínio (Al) e Potássio (K).

\section{REFERÊNCIAS}

ANDREOTTI, M; SORIA, J. E.; COSTA, N. R.; GAMEIRO, R. A.; REBONATTI, M. D. Acúmulo de nutrientes e decomposição do palhiço de cana em função de doses de vinhaça. Bioscience Journal, v. 31, n. 2, p. 563-576, 2015. Disponível em: <http://www.seer.ufu.br/index.php/biosciencejournal/article/view/22426/16145>. doi: http://dx.doi.org/10.14393/BJ-v31n2a2015-22426

BONINI, I.; PESSOA, M. J. G.; JUNIOR, S. S. Fases da produção agrícola matogrossense: tipos de exploração, origem dos agricultores e impactos na conservação ambiental em Alta Floresta (MT). Novos Cadernos NAEA, v. 16, n. 01, p. 173-190, $2013 . \quad$ Disponível em: https://periodicos.ufpa.br/index.php/ncn/article/view/975/1771>. doi: http://dx.doi.org/10.5801/ncn.v16i1.975

BRANDÃO, F. J. C. Caracterização de um latossolo em sistemas agroflorestais e mata com o uso de análise estatística multivariada. Tese (Doutorado em Agronomia (Ciência do Solo)), Faculdade de Ciências Agrárias e Veterinárias UNESP, Jaboticabal. 2013.

CAPELESSO, A. J.; CAZELLA, A. A. Indicador de sustentabilidade dos agroecossistemas: estudo de caso em áreas de cultivo de milho. Ciência Rural, v. 
43, n. 12, p. 2297-2303, 2013. Disponível em: <http://www.scielo.br/pdf/cr/v43n12/a33113cr2012-0634.pdf>.

CARNEIRO, W. J. de O. SILVA, C. A.; MUNIZ, J. A.; SAVIAN, T. V. Mineralização de nitrogênio em latossolos adubados com resíduos orgânicos. Revista Brasileira de Ciência do Solo, v. 37, n. 3, p. 715-725, 2013. Disponível:< http://www.scielo.br/pdf/rbcs/v37n3/18.pdf>. doi: http://dx.doi.org/10.1590/S010006832013000300018

COSTA, E. M.; SILVA, H. F.; RIBEIRO, P. R. de A. Matéria orgânica do solo e o seu papel na manutenção e produtividade dos sistemas agrícolas. Enciclopédia Biosfera -Centro Científico Conhecer, v.9, n.17; p. 1842-1860, 2013. Disponível em:<http://www.conhecer.org.br/enciclop/2013b/CIENCIAS\%20AGRARIAS/materia $\% 20$ organica.pdf>.

DECHEN, S. C. F.; TELLES, T. S.; GUIMARÃES, M. F.; MARIA, I. C. Perdas e custos associados à erosão hídrica em função de taxas de cobertura do solo. Bragantia, v. 74, n. 2, p.224-233, 2015. Disponível em:< http://www.scielo.br/pdf/brag/v74n2/0006-8705-brag-74-2-224.pdf>. doi: http://dx.doi.org/10.1590/1678-4499.0363

DUARTE et al. Alterações dos atributos físicos e químicos de um Neossolo após aplicação de doses de manipueira. Rev. Brasileira de Engenharia Agrícola e Ambiental, v.17, n. 9, p. 938-946, 2013. Disponível em:<http://www.scielo.br/scielo.php?pid=S141543662013000900005\&script=sci_abs tract\&tlng=pt>. doi: http://dx.doi.org/10.1590/S1415-43662013000900005.

EMBRAPA. Empresa Brasileira de Pesquisa Agropecuária. Indicadores de sustentabilidade em agroecossistemas. 1. ed. Jaguariúna, SP: Embrapa Meio Ambiente, 2003.

FERREIRA, D. F. Sisvar: a Guide for its Bootstrap procedures in multiple comparisons. Ciências e agrotecnologia. [online], vol.38, n.2, p. 109-112, 2014. Disponível em: <ISSN 1413-7054. http://dx.doi.org/10.1590/S1413$70542014000200001>$.

FREITAS, L. de et al. Avaliação de atributos químicos e físicos de solos com diferentes texturas cultivados com cana-de-açúcar. Enciclopédia Biosfera - Centro Científico Conhecer, v.9, n.17; p. 362-374, 2013. Disponível em: < http://www.conhecer.org.br/enciclop/2013b/CIENCIAS\%20AGRARIAS/avaliacao\%20 de\%20atributos.pdf>

GUIMARÃES et al. Análise dos impactos ambientais de um incêndio florestal. Revista Agrarian Academy - Centro Científico Conhecer, v. 01, n. 01, p. 38-60, 2014. Disponível em: <http://www.conhecer.org.br/Agrarian\%20Academy/2014a/analise\%20dos\%20impac tos.pdf>

LISBOA, F. M.; MIRANDA, P. B. Análise de Atributos Físicos e Químicos de Solo Submetido a Diferentes Manejos no Sudeste Paraense. Revista ENCICLOPÉDIA BIOSFERA, Centro Científico Conhecer - Goiânia, v.15 n.28; p.637 2018 
Agroecossistemas, $\quad$ v. 6, n. 1, p. 1-9, $2014 . \quad$ Disponível: $<$ https://periodicos.ufpa.br/index.php/agroecossistemas/article/view/1558/2298>. doi: http://dx.doi.org/10.18542/ragros.v6i1.1558

MACEDO, R. K de. Ambiente e sustentabilidade: metodologias para gestão. 1 . ed. Rio de Janeiro, RJ: LTC, 2015.

MAIA, C. E. Qualidade ambiental em solo com diferentes ciclos de cultivo do meloeiro irrigado. Ciência Rural, v.43, n.4, p.603-609, 2013. Disponível em: < http://www.scielo.br/pdf/cr/v43n4/a11413cr6051.pdf>

MARCHINI, D. C. et al. Matéria orgânica, infiltração e imagens tomográficas de Latossolo em recuperação sob diferentes tipos de manejo. Revista Brasileira de Engenharia Agrícola e Ambiental, v. 19, n. 06, p. 574-580, 2015. Disponível em: $<$ http://www.scielo.br/scielo.php?pid=S1415-

43662015000600574\&script=sci_abstract\&tlng=pt>.

doi: http://dx.doi.org/10.1590/1807-1929/agriambi.v19n6p574-580

MENEGHIN, M. F. S. et al. Avaliação da disponibilidade de nitrogênio no solo para o trigo em latossolo vermelho do distrito federal. Revista Brasileira de Ciência do Solo, v. 32, n. 5, p. 1941-1948, 2008. Disponível em:<http://www.scielo.br/scielo.php?pid=S010006832008000500015\&script=sci_abs tract\&tlng=pt>. doi: http://dx.doi.org/10.1590/S0100-06832008000500015

MOREIRA, G. C.; TEXEIRA, E. C. Política pública de pesquisa agropecuária no Brasil. Revista de Política Agrícola, v. 23, n. 3, p. 5-17, 2014. Disponível em: < https://seer.sede.embrapa.br/index.php/RPA/article/view/940/833>

NATALE, W.; ROZANE, D. E.; PARENT, L. E.; PARENT, S. E. Acidez do solo e calagem em pomares de frutíferas tropicais. Revista Brasileira de Fruticultura, v. 34, n. 4, p. 1294-1306, 2012. Disponível:< http://www.scielo.br/pdf/rbf/v34n4/41.pdf>. doi: http://dx.doi.org/10.1590/S0100-29452012000400041

PEREIRA, E. L.; NASCIMENTO, J. S. Efeitos do Pronaf sobre a produção agrícola familiar dos municípios tocantinenses. Revista de Economia e Sociologia Rural, v. 52, n. $01, \quad$ p. 139-156, 2014. Disponível em:< http://www.scielo.br/scielo.php?script=sci_arttext\&pid=S0103-20032014000100008>. doi: http://dx.doi.org/10.1590/S0103-20032014000100008

SANTOS, J. G.; CÂNDIDO, G. A. Sustentabilidade e agricultura familiar: um estudo de caso em uma associação de agricultores rurais. Revista de Gestão Social e Ambiental, v. 7, n. 1, p. 69-85, 2013. Disponível em: $<$ http://www.spell.org.br/documentos/ver/15062/sustentabilidade-e-agriculturafamiliar--um-estudo-de-caso-em-uma-associacao-de-agricultores-rurais/i/pt-br>

SANTOS, D. R dos.; GATIBONI, L.C.; KAMINSKI, J. Fatores que afetam a disponibilidade do fósforo e o manejo da adubação fosfatada em solos sob sistema plantio direto. Ciência Rural, v.38, n. 2, 2008. Disponível em: $<$ http://www.scielo.br/scielo.php?script=sci_arttext\&pid=S0103-

84782008000200049>. doi: http://dx.doi.org/10.1590/S0103-84782008000200049 
SARTO, M. V. M. et al. Atributos químicos do solo e desenvolvimento da cultura do trigo em função da adubação silicatada. Revista Agrarian, v.7, n.25, p.390-400, 2014.Disponível em:<http://ojs.ufgd.edu.br/index.php/agrarian/article/view/2400/1906 $>$.

SILVA, A. O. da. A fertirrigação e o processo de salinização de solos em ambiente protegido. Nativa: Pesquisas agrárias e ambientais, v. 02, n. 03, p. 180-186, 2014. Disponível em:<http://periodicoscientificos.ufmt.br/ojs/index.php/nativa/index>. doi: http://dx.doi.org/10.14583/2318-7670.v02n03a10

SILVA, A. O. da; SILVA, E. F. F. e; KLAR, A. E. Manejo da fertirrigação e salinidade do solo no crescimento da cultura da beterraba. Revista Engenharia Agrícola, v. 35, n. 2, p. 230-241. 2015. Disponível em: <http://www.scielo.br/pdf/eagri/v35n2/1809-4430-eagri-35-2-0230.pdf>. doi: http://dx.doi.org/10.1590/1809-4430-

SILVA, K. R.; AMARAL, E. T. O. P.; OlIVEIRA, A. N de.; MELLO, A. H de.; OLIVEIRA, G. F. de. Indicadores químicos do solo sob diferentes usos e manejo no Lote 31 do projeto de assentamento Veneza no Sudeste do Pará. Revista Agroecossistemas. v. $9 . \quad$ n. 1. p. 227-235, 2017. Disponível em:<https://periodicos.ufpa.br/index.php/agroecossistemas/article/download/4778/44 02>

VAZ, C. A. B.; DA SILVEIRA, G. L. O modelo PEIR e base SIG no diagnóstico da qualidade ambiental em sub-bacia hidrográfica urbana. Revista Brasileira de Recursos Hídricos, v. 19, n. 02, p. 281-298, 2014. Disponível em: <https://www.abrh.org.br/SGCv3/index.php?PUB=1\&ID=165\&SUMARIO=4757>. doi: 10.21168/rbrh.v19n2.p281-298

VICENTE, G. C. M. P.; ARAÚJO, F. F. de. Uso de indicadores microbiológicos e de fertilidade do solo em áreas de pastagens. Semina: Ciências Agrárias, v. 34, n. 1, p. 137-146, 2013. Disponível em: <http://www.uel.br/revistas/uel/index.php/semagrarias/article/viewFile/9971/12018>. doi: 10.5433/1679-0359.2013v34n1p137 